\title{
Diversity in 113 cowpea [Vigna unguiculata (L) Walp] accessions assessed with 458 SNP markers
}

\author{
Kenneth F Egbadzor ${ }^{1,2^{*}}$, Kwadwo Ofori ${ }^{5}$, Martin Yeboah ${ }^{1}$, Lawrence M Aboagye ${ }^{2}$, Michael O Opoku-Agyeman ${ }^{3}$, \\ Eric Y Danquah ${ }^{1}$ and Samuel K Offei ${ }^{4}$
}

\begin{abstract}
Single Nucleotide Polymorphism (SNP) markers were used in characterization of 113 cowpea accessions comprising of 108 from Ghana and 5 from abroad. Leaf tissues from plants cultivated at the University of Ghana were genotyped at KBioscience in the United Kingdom. Data was generated for 477 SNPS, out of which 458 revealed polymorphism. The results were used to analyze genetic dissimilarity among the accessions using Darwin 5 software. The markers discriminated among all of the cowpea accessions and the dissimilarity values which ranged from 0.006 to 0.63 were used for factorial plot. Unexpected high levels of heterozygosity were observed on some of the accessions. Accessions known to be closely related clustered together in a dendrogram drawn with WPGMA method. A maximum length sub-tree which comprised of 48 core accessions was constructed. The software package structure was used to separate accessions into three groups, and the programme correctly identified varieties that were known hybrids. The hybrids were those accessions with numerous heterozygous loci. The structure plot showed closely related accessions with similar genome patterns. The SNP markers were more efficient in discriminating among the cowpea germplasm than morphological, seed protein polymorphism and simple sequence repeat studies reported earlier on the same collection.
\end{abstract}

Keywords: Characterization; Cowpea; Diversity; Genetic; Genotype; Markers; SNPs

\section{Introduction}

Cowpea [Vigna unguiculata (L) Walp] is an important staple food crop in Ghana and many other parts of the world (Obembe 2008; Timko and Singh 2008). The crop is also used as animal feed. As a legume, cowpea fixes nitrogen and therefore, contributes to soil improvement. Compared with other important staples such as maize, rice, yams and plantains in Ghana, most cowpea varieties have shorter maturity period ( 55 days for some varieties) making it a crop of choice to address hunger and malnutrition.

Cowpea is known to be relatively drought tolerant (Boukar et al. 2011; Muchero et al. 2009) and this attribute results in its cultivation mainly in the savanna and forest - savanna transitional zones of West Africa. Resource inputs in cowpea production are relatively low

\footnotetext{
* Correspondence: kenfafa@yahoo.com

${ }^{1}$ West Africa Centre for Crop Improvement, University of Ghana, Legon, Accra, Ghana

${ }^{2}$ CSIR - Plant Genetic Resources Research Institute, Bunso, Ghana

Full list of author information is available at the end of the article
}

compared to those used in the production of other major staples, making its cultivation affordable by resource poor farmers (Muchero et al. 2009).

Cowpea is primarily a self-pollinating crop and its genetic base is considered to be narrow (Sharawy and El-Fiky 2002; Fang et al. 2005; Asare et al. 2010). Presence of diversity in the germplasm of crops is essential for successful crop improvement (Varshney et al. 2007). Limited genetic diversity poses a threat to the survival of a species as this limits ability to respond to changes in climate, pathogen populations and agricultural practices (Manifesto et al. 2001). The source of genetic resources for crop improvement is the available germplasm in genebanks and this need to be assessed for availability of useful traits for crop improvement (Tan et al. 2012).

Cowpea is one of the most researched crops at the genebank of the Council for Scientific and Industrial Research - Plant Genetic Resources Research Institute (CSIR - PGRRI) (Bennett-Lartey 1992; Asare et al. 2010). CSIR - PGRRI is situated at Bunso, in the Eastern Region of Ghana. Most of these germplasm were collected in the 
1980s and 90s from different parts of Ghana. These have been characterized based on morphological (Bennett-Lartey 1992) seed protein (Oppong-Konadu et al. 2005) and Simple Sequence Repeat (SSR) differences (Asare et al. 2010).

Single Nucleotide Polymorphism markers (SNPs) are powerful tools in genetic diversity study in living organisms (Deulvot et al. 2010). SNPs are more effective in diversity assessment compared with other markers such as AFLPs and SSRs (Varshney et al. 2007). Using morphological markers, Cobbinah et al. (2011) observed multiple duplicates within cowpea germplasm in Ghana. Reason for the high number of duplicates was the limited number of morphological markers and the low genetic variability these markers revealed. Asare et al. (2010) using SSRs could also not discriminate between some accessions of the cowpea germplasm in reference. It is critical, for the purposes of efficiency, that the best available tool for genetic diversity assessment is deployed.

SNPs are numerous in the genome of plants and other living organisms (Galeano et al. 2009; Deulvot et al. 2010) and they serve as good tools for diversity studies (Acquaah 2007; Varshney et al. 2007). SNPs may be the best choice for diversity studies at the moment. As of 2012, there had been no report on cowpea diversity studies that used SNPs markers (Tan et al. 2012). However, in 2013, Huynh et al. (2013) and Lucas et al. (2013b) reported their diversity work on worldwide cowpea collection. The objectives of this study were to use SNP markers to:

1. Assess genetic diversity within cowpea germplasm assembled from CSIR - PGRRI, Bunso, Ghana and abroad.

2. Use diversity information to select a core cowpea germplasm collection for breeding purposes.

3. Help guide future international research in cowpea breeding.

\section{Materials and methods \\ Plant materials}

A total of 113 cowpea accessions were characterized. These included 102 accessions collected from different parts of Ghana. One hundred and one accessions of the 102 are being conserved at CSIR - PGRRI genebank at
Bunso, Ghana, while one accession (WACCI01) was obtained from West Africa Centre for Crop Improvement (WACCI), University of Ghana. Four accessions were breeding lines selected from accession GH4524 based on seed coat colour differences (Figure 1). Six of the accessions were improved varieties in cultivation in Ghana, namely: 'Asontem,' 'Nhyira, 'Zaayura, 'Tona, 'Paddy Twua' and 'Bawuta'. In addition there were two lines each from University of California Riverside (UCR779 and CB27) and International Institute of Tropical Agriculture (IITA) in Nigeria (IT97K-556-6 and IT82E-18). The accession labeled "market" is one of the popular cowpea imported to Ghana from Togo and was, therefore, included in the imported accessions. All the accessions are listed in Table 1.

Seeds were germinated in sterilized top soil contained in nursery boxes at the Crop Science Department Garden, University of Ghana. Leaf discs of one week old plants were sampled from one plant per accession and shipped to the laboratory of KBiosciences in the United Kingdom where genomic DNA was extracted. The DNA samples were genotyped using 500 SNPs from the cowpea panel (Muchero et al. 2009; Lucas et al. 2011).

\section{Markers used}

The SNP markers used were distributed across the cowpea genome. Figure 2 shows a map of the eleven linkage groups of cowpea and indicate the positions of the markers on the cowpea genome. The length of each linkage group and their respective number of markers are inserted. Twelve out of the 477 SNP markers were unmapped, thus summing up to 465 instead of 477 markers (Figure 2).

\section{Data analysis}

The software Darwin (Perrier and Jacquemoud-Collet 2006) was used to analyze the data. Dissimilarity was calculated using simple matching coefficient after Perrier et al. (2003) as follows:

$$
\underset{\mathrm{dij}=1-1 / \mathrm{L} \sum \mathrm{ml} / \pi}{\mathrm{L}=1}
$$

Where:

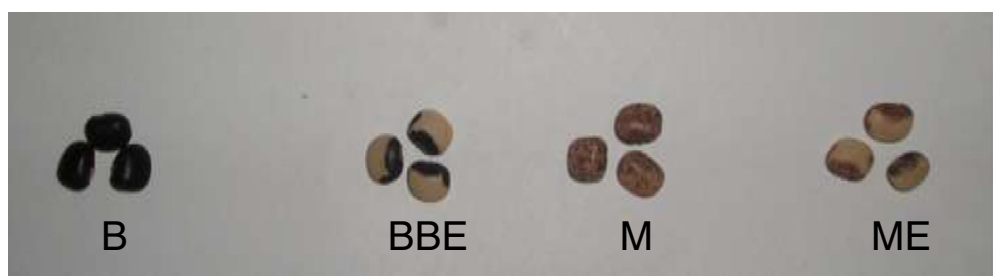

Figure 1 Different lines of Gh4524 based on seed coat colour differences: B, BBE, M and ME for black, big black eye, mottle and mottle eye respectively. 
Table 1 Passport data of the cowpea accessions used for the experiment

\begin{tabular}{|c|c|c|c|c|c|c|c|c|}
\hline GH number & Local name & Collection date & Region & Lat & Long & Seed colour & Structure ID & $\%$ Hetero \\
\hline GH1622 & Ayi-dze & $21-12-82$ & Volta & $06^{\circ} 35^{\prime} \mathrm{N}$ & $00^{\circ} 27^{\prime} E$ & Black & 81 & 0.43 \\
\hline GH1630* & Asedua & $01-12-83$ & Volta & $06^{\circ} 29^{\prime} \mathrm{N}$ & $00^{\circ} 10^{\prime} \mathrm{E}$ & Black & 59 & 0.71 \\
\hline GH1665* & Asedua & $26-11-82$ & Eastern & & & Cream & 80 & 31.45 \\
\hline GH1667 & AduaNsawa & $30-11-82$ & Eastern & $06^{\circ} 40^{\prime} \mathrm{N}$ & $01^{\circ} 20^{\prime} \mathrm{W}$ & Brown & 29 & 0.21 \\
\hline GH2279 & Sanji & 14-10-87 & North & $09^{\circ} 15^{\prime} \mathrm{N}$ & $00^{\circ} 37^{\prime} \mathrm{W}$ & Red & 96 & 0.67 \\
\hline $\mathrm{GH} 2280^{*}$ & Sanji & 14-10-87 & North & $09^{\circ} 15^{\prime} \mathrm{N}$ & $02^{\circ} 10^{\prime} \mathrm{W}$ & Brown & 85 & 0.43 \\
\hline $\mathrm{GH} 2281^{*}$ & Sanji & 14-10-87 & North & & & Dark & 95 & 0.24 \\
\hline $\mathrm{GH} 2282^{*}$ & Sanji & $14-10-87$ & North & $09^{\circ} 55^{\prime \prime} \mathrm{N}$ & $00^{\circ} 07^{\prime} \mathrm{W}$ & Black & 84 & 0.00 \\
\hline $\mathrm{GH} 2284^{*}$ & Sanji & 14-10-87 & North & $09^{\circ} 18^{\prime} \mathrm{N}$ & $02^{\circ} 25^{\prime} \mathrm{W}$ & Red & 107 & 6.99 \\
\hline $\mathrm{GH} 2288^{*}$ & Isagi & $14-10-87$ & North & $09^{\circ} 26^{\prime} \mathrm{N}$ & $02^{\circ} 00^{\prime} \mathrm{W}$ & Black & 41 & 0.85 \\
\hline GH2291* & Sanji & $15-10-87$ & North & $09^{\circ} 13^{\prime} \mathrm{N}$ & $01^{\circ} 02^{\prime} \mathrm{W}$ & Red & 68 & 3.81 \\
\hline GH2293 & Sanji & 15-10-87 & North & $09^{\circ} 29^{\prime} \mathrm{N}$ & $01^{\circ} 13^{\prime} \mathrm{W}$ & Red & 74 & 0.22 \\
\hline GH2294* & & $15-10-87$ & North & $09^{\circ} 29^{\prime} \mathrm{N}$ & $01^{\circ} 13^{\prime} \mathrm{W}$ & Mottled & 102 & 0.51 \\
\hline GH2296 & Sanji & 15-10-87 & North & $10^{\circ} 21^{\prime} \mathrm{N}$ & $00^{\circ} 35^{\prime} \mathrm{W}$ & Red & 53 & 0.21 \\
\hline GH2306 & Bonda & $16-10-87$ & Upper West & $10^{\circ} 40^{\prime} \mathrm{N}$ & $02^{\circ} 01^{\prime} \mathrm{W}$ & Black & 101 & 0.21 \\
\hline GH2307 & Bondawa & 16-10-87 & Upper West & $10^{\circ} 53^{\prime} \mathrm{N}$ & $02^{\circ} 07^{\prime} \mathrm{W}$ & Black & 92 & 0.21 \\
\hline GH2309* & Bibitakone & 17-10-87 & Upper West & $10^{\circ} 50^{\prime} \mathrm{N}$ & $03^{\circ} 15^{\prime} \mathrm{W}$ & Black & 25 & 7.86 \\
\hline GH2312 & Dapiala & 17-10-87 & Upper West & $10^{\circ} 15^{\prime} \mathrm{N}$ & $02^{\circ} 27^{\prime} \mathrm{W}$ & Red & 17 & 0.45 \\
\hline $\mathrm{GH} 2314^{*}$ & Bengah & 17-10-87 & Upper West & $10^{\circ} \mathrm{O}^{\prime} \mathrm{N}$ & $02^{\circ} 24^{\prime} \mathrm{W}$ & Mottled & 76 & 2.50 \\
\hline GH2316* & Bengah & $17-10-87$ & Upper West & $09^{\circ} 26^{\prime} \mathrm{N}$ & $02^{\circ} 30^{\prime} \mathrm{W}$ & Mottled & 106 & 0.23 \\
\hline GH2317 & Achibe & 17-10-87 & North & $09^{\circ} 32^{\prime} \mathrm{N}$ & $02^{\circ} 36^{\prime} \mathrm{W}$ & Mottled & 90 & 0.21 \\
\hline $\mathrm{GH} 2323^{*}$ & Bengah & 19-10-87 & North & $08^{\circ} 25^{\prime} \mathrm{N}$ & $02^{\circ} 17^{\prime} \mathrm{W}$ & White & 88 & 1.49 \\
\hline GH2325 & Asedua & $30-11-87$ & Eastern & $06^{\circ} 22^{\prime} \mathrm{N}$ & $00^{\circ} 24^{\prime} \mathrm{W}$ & Cream/Mixed & 91 & 0.43 \\
\hline GH2326 & Asedua & $30-11-87$ & Eastern & $06^{\circ} 22^{\prime} \mathrm{N}$ & $00^{\circ} 24^{\prime} \mathrm{W}$ & White & 46 & 0.21 \\
\hline GH2328 & Asedua & $30-11-87$ & Eastern & $06^{\circ} 22^{\prime} \mathrm{N}$ & $00^{\circ} 24^{\prime} \mathrm{W}$ & Red & 86 & 0.22 \\
\hline GH2329 & Asedua & $30-11-87$ & Eastern & $06^{\circ} 22^{\prime} \mathrm{N}$ & $00^{\circ} 24^{\prime} \mathrm{W}$ & White & 55 & 0.21 \\
\hline GH2330 & Asedua & $30-11-87$ & Eastern & $06^{\circ} 22^{\prime} \mathrm{N}$ & $00^{\circ} 24^{\prime} \mathrm{W}$ & Red & 27 & 0.64 \\
\hline GH2331 & Asedua & $30-11-87$ & Eastern & $06^{\circ} 22^{\prime} \mathrm{N}$ & $00^{\circ} 24^{\prime} \mathrm{W}$ & Mottled & 54 & 0.42 \\
\hline GH2332 & Asedua & $30-11-87$ & Eastern & $06^{\circ} 22^{\prime} \mathrm{N}$ & $00^{\circ} 24^{\prime} \mathrm{W}$ & White & 47 & 0.21 \\
\hline GH2333 & AduaNsawa & $30-11-87$ & Eastern & $06^{\circ} 22^{\prime} \mathrm{N}$ & $00^{\circ} 35^{\prime} \mathrm{W}$ & Mottled & 112 & 0.85 \\
\hline $\mathrm{GH} 2334^{*}$ & AduaNsawa & $30-11-87$ & Eastern & $06^{\circ} 22^{\prime} \mathrm{N}$ & $00^{\circ} 35^{\prime} \mathrm{W}$ & Cream & 103 & 0.21 \\
\hline GH2335 & AduaNsawa & $12-1-87$ & Eastern & $06^{\circ} 22^{\prime} \mathrm{N}$ & $00^{\circ} 35^{\prime} \mathrm{W}$ & Red & 100 & 0.21 \\
\hline GH2340 & AduaNsawa & $12-1-87$ & Eastern & $06^{\circ} 34^{\prime} \mathrm{N}$ & $00^{\circ} 35^{\prime} \mathrm{W}$ & Black & 42 & 0.00 \\
\hline GH2341 & AduaNsawa & $12-1-87$ & Eastern & $06^{\circ} 38^{\prime} \mathrm{N}$ & $00^{\circ} 34^{\prime} \mathrm{W}$ & White & 24 & 0.21 \\
\hline $\mathrm{GH} 2342^{*}$ & AduaNsawa & $12-1-87$ & Eastern & $06^{\circ} 38^{\prime} \mathrm{N}$ & $00^{\circ} 34^{\prime} \mathrm{W}$ & Red & 83 & 0.63 \\
\hline $\mathrm{GH} 2347^{*}$ & Yor & $18-12-87$ & Eastern & & & Black & 97 & 0.00 \\
\hline $\mathrm{GH} 2492^{*}$ & - & 20-10-87 & Ashanti & & & White & 62 & 1.35 \\
\hline $\mathrm{GH} 3667^{*}$ & Ayi & 23-10-93 & Volta & $06^{\circ} 18^{\prime} E$ & $0^{\circ} 11 ' \mathrm{~N}$ & Dark & 89 & 0.21 \\
\hline GH3668 & Ayi & 23-10-93 & Volta & $06^{\circ} 18^{\prime} \mathrm{E}$ & $0^{\circ} 11^{\prime} \mathrm{N}$ & Black & 43 & 0.43 \\
\hline GH3669 & Ayi & 23-10-93 & Volta & $06^{\circ} 18^{\prime} E$ & $0^{\circ} 11 ' \mathrm{~N}$ & Black & 28 & 0.21 \\
\hline Gh3670* & Ayi & 23-10-93 & Volta & $06^{\circ} 35^{\prime} \mathrm{N}$ & $0^{\circ} 06^{\prime} \mathrm{E}$ & Brown & 94 & 0.43 \\
\hline Gh3673 & Ayi & 24-10-93 & Volta & $06^{\circ} 41^{\prime} \mathrm{N}$ & $0^{\circ} 17^{\prime} \mathrm{E}$ & Black & 69 & 0.64 \\
\hline Gh3674* & Eveyi & $24-10-93$ & Volta & $06^{0} 34^{\prime} \mathrm{N}$ & $0^{\circ} 18^{\prime}$ & Black & 77 & 0.63 \\
\hline Gh3675 & Ase fita & $25-10-93$ & Eastern & $06^{\circ} 13^{\prime} \mathrm{N}$ & $0^{\circ} 5^{\prime} E$ & Black & 26 & 0.64 \\
\hline
\end{tabular}


Table 1 Passport data of the cowpea accessions used for the experiment (Continued)

\begin{tabular}{|c|c|c|c|c|c|c|c|c|}
\hline Gh3677* & Yor & $25-10-93$ & Eastern & $06^{\circ} 06^{\prime} \mathrm{N}$ & $0^{\circ} 12^{\prime} \mathrm{W}$ & Brown & 99 & 0.43 \\
\hline Gh3685 & Asedua & 30-10-93 & Eastern & $07^{\circ} 16^{\prime} \mathrm{N}$ & $02^{\circ} 19^{\prime} \mathrm{W}$ & Black & 108 & 0.43 \\
\hline Gh3689 & Sanji & $1-11-93$ & Eastern & $08^{\circ} 54^{\prime} \mathrm{N}$ & $0^{\circ} 39^{\prime} \mathrm{N}$ & Brown & 34 & 0.43 \\
\hline GH3701 & Sanji & $11-2-93$ & Eastern & $06^{\circ} 10^{\prime} w$ & $0^{\circ} 03^{\prime} \mathrm{N}$ & Brown & 93 & 0.42 \\
\hline Gh3706* & Benga & $4-11-93$ & North & $09^{\circ} 50^{\prime} \mathrm{N}$ & $0^{\circ} 29^{\prime} \mathrm{W}$ & Brown & 87 & 0.00 \\
\hline GH3703 & Tua & $11-2-93$ & North & & & Red & 50 & 0.47 \\
\hline GH3708* & Sega & $11-4-93$ & North & $09^{\circ} 20^{\prime} \mathrm{W}$ & $02^{\circ} 20^{\prime} \mathrm{N}$ & Mottled & 105 & 0.45 \\
\hline GH3710* & Tua & $11-5-93$ & North & & & Dark & 109 & 0.21 \\
\hline Gh4028 & Adua nsawa & $19-5-96$ & North & & & Red & 57 & 0.23 \\
\hline GH4524 & Yor & 29-7-96 & Accra & & & Black & $1,2,3,4$ & 0.24 \\
\hline GH4529 & Tolonye & $30-7-96$ & Accra & & & Mottled & 65 & 0.43 \\
\hline GH4530 & Yor & $30-7-96$ & Accra & & & Brown & 18 & 0.43 \\
\hline GH4532 & Ayiyibor & $31-7-96$ & Volta & & & Red & 61 & 0.65 \\
\hline GH4533* & Ayi & $31-7-96$ & Volta & & & Cream & 82 & 1.32 \\
\hline GH4537* & Ayi & 08-1-96 & Volta & & & Brown & 60 & 0.22 \\
\hline GH4541 & Ayi & 08-1-96 & Volta & & & Mttled & 52 & 0.63 \\
\hline GH4546 & Ayi & 08-3-96 & Volta & & & Dark & 70 & 0.21 \\
\hline GH4769* & Bianga & $22-10-96$ & Upper West & & & Red & 63 & 0.42 \\
\hline GH4771 & Bianga & $22-10-96$ & Upper West & & & Black & 38 & 0.21 \\
\hline GH4778 & Gonja & 27-10-96 & North & & & Red & 23 & 0.21 \\
\hline GH5038 & Vakli & $11-4-96$ & Volta & & & Cream & 33 & 0.21 \\
\hline GH5039 & Ekye & $11-4-96$ & Eastern & & & Red & 66 & 0.44 \\
\hline GH5040* & Yor & $11-5-96$ & Eastern & & & Red & 40 & 0.21 \\
\hline GH5044 & Yor & $11-6-96$ & Eastern & & & Red & 39 & 0.21 \\
\hline GH5045 & Yor & $11-6-96$ & Eastern & & & Red & 44 & 0.66 \\
\hline GH5048 & AduaNsadua & $11-6-96$ & Eastern & & & Red & 37 & 0.21 \\
\hline GH5049 & Asedua & $11-6-96$ & Eastern & & & Red & 72 & 0.21 \\
\hline GH5050 & Asedua & $11-8-96$ & Ashanti & & & Red & 32 & 0.42 \\
\hline GH5344 & Asedua & $11-6-96$ & Ashanti & & & Red & 48 & 0.42 \\
\hline Gh5346 & Asedua & $9-11-96$ & Ashanti & & & Brown & 51 & 0.64 \\
\hline GH6045* & Soronko & & Ashanti & & & Reddish Brown & 30 & 0.63 \\
\hline GH6060* & Ayiyi & 28-8-98 & Eastern & & & Cream & 22 & 0.21 \\
\hline GH7167 & Tue & $18-2-03$ & Upper East & & & White & 104 & 0.42 \\
\hline GH7174 & Tse & $18-2-03$ & Upper East & & & Cream & 49 & 0.42 \\
\hline GH7178* & Benga & $19-2-03$ & Upper East & & & Red & 21 & 36.49 \\
\hline Gh7185 & Sona & $19-2-03$ & Upper East & & & Black & 71 & 0.21 \\
\hline GH7187 & Goatana & $20-2-03$ & Upper East & & & Black & 13 & 0.21 \\
\hline Gh7218 & Sona & 04-1-03 & Upper West & & & Dark & 58 & 0.00 \\
\hline GH7222 & Bondabene & 04-1-03 & Upper West & & & Brown & 56 & 0.66 \\
\hline GH7224 & Sompla & 04-1-03 & Upper West & & & Dark & 31 & 0.21 \\
\hline GH7226* & Bene & 04-1-03 & Upper West & & & White & 111 & 0.43 \\
\hline GH7228 & Bene & $04-2-03$ & Upper West & & & Dark & 45 & 3.24 \\
\hline GH7229 & Bene & $04-2-03$ & Upper West & & & Dark & 19 & 0.21 \\
\hline GH7230* & Bene & $04-2-03$ & Upper West & & & Brown & 79 & 0.24 \\
\hline GH7231 & Bene & $04-2-03$ & Upper West & & & Dark & 67 & 2.44 \\
\hline
\end{tabular}


Table 1 Passport data of the cowpea accessions used for the experiment (Continued)

\begin{tabular}{|c|c|c|c|c|c|c|}
\hline GH7233 & Bene & $04-2-03$ & Upper West & Brown & 35 & 0.42 \\
\hline $\mathrm{GH} 7234^{*}$ & Bene & $04-2-03$ & Upper West & Dark & 110 & 20.09 \\
\hline GH7235 & Bene & $04-2-03$ & Upper West & Dark & 75 & 0.21 \\
\hline GH7243 & & $04-2-03$ & Upper West & Dark & 78 & 0.42 \\
\hline Gh7245* & Sonorni & $1-4-03$ & Upper West & Brown & 98 & 0.43 \\
\hline Gh7273 & & $1-4-03$ & Upper West & White & 73 & 0.63 \\
\hline GH7875 & Asedua & $15-3-06$ & Eastern & Red & 20 & 0.21 \\
\hline GH7888* & Asetenapa & $16-8-06$ & Ashanti & Cream & 36 & 0.63 \\
\hline IT97K556 & & & IITA, Nigeria & Brown & 5 & 0.43 \\
\hline IT82E-18* & & & IITA, Nigeria & Brown & 6 & 0.88 \\
\hline UCR 779* & & & UCR, USA & Brown & 7 & 0.21 \\
\hline CB $27^{*}$ & & & UCR, USA & White & 8 & 0.64 \\
\hline Bawuta* & & & CSIR - SARI & White & 14 & 0.21 \\
\hline Tona* & & & $C S I R-C R I$ & Brown & 9 & 0.42 \\
\hline Nhyira* & & & $C S \mid R-C R I$ & Cream & 10 & 0.42 \\
\hline PaddyT* & & & CSRI - SARI & White & 15 & 0.21 \\
\hline Asontem* & & & CSIR - CRI & Red & 16 & 2.77 \\
\hline Market* & & & Volta (Ho) & White & 64 & 2.70 \\
\hline WACCIO1* & & & Legon, Accra & Dark & 11 & 0.66 \\
\hline Zayuraa* & & & CSIR - SARI & White & 12 & 1.07 \\
\hline
\end{tabular}

Note: Lat Latitude, Long Longitude, Hetero Heterozygosity. * - Accessions selected as core for further studies.

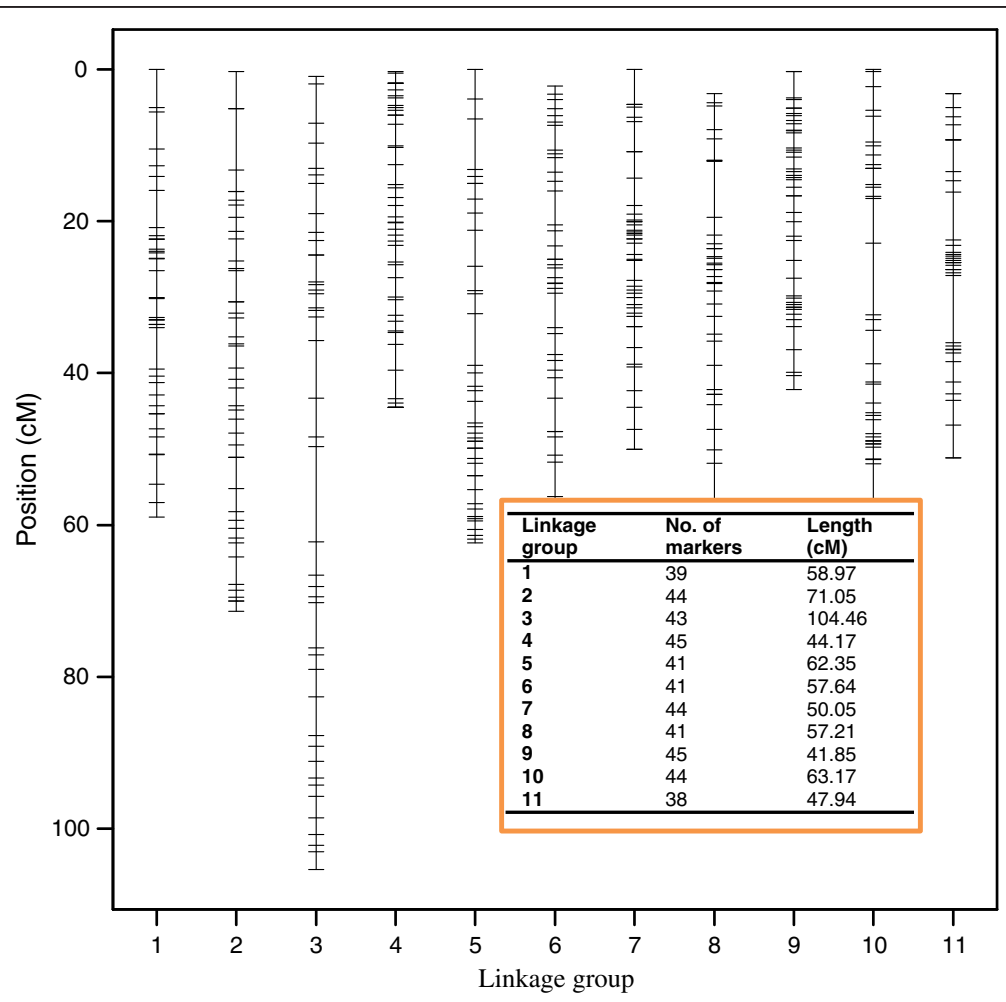

Figure 2 The SNP markers used for the experiment - Length of linkage group, number of markers and their positions. 
dij: dissimilarity between units $i$ and $j$

$L$ : number of loci

$\pi:$ ploidy

$m l$ : number of matching alleles for locus $l$ (Perrier et al. 2003).

The calculated dissimilarity coefficient was used to construct a tree using the hierarchical clustering of Weighted Paired Group Method with Arithmetic Mean (WPGMA). It was used for a factorial plot and a Maximum Length sub-tree was constructed to select a representative core accessions.

Detection of the underlying genetic population among the studied cowpea accessions was carried out with the Structure software (Pritchard et al. 2000). Three populations $(K=3)$ were assumed and indicated with blue, green and red colours. Different numbers were tried for $\mathrm{K}$ and finally 3 accepted with admixture ancestry model. Length of burnin was 5000 and the number of MCMC was set at 10000 .

\section{Results}

\section{Allelic diversity}

Out of the 477 SNPs, 458 were polymorphic. SNP data revealed that some of the markers although polymorphic, only few, sometimes just one genotype had them in the collection. The percentage of the cowpea accessions that shared common allele per locus, thus, varied greatly: from $0 \%$ versus $100 \%$ to $50 \%$ versus $50 \%$ (refer to Additional file 1).

\section{Heterozygosity}

Some of the cowpea accessions were heterozygous at some of the marker loci. Heterozygosity at a locus may indicate accessions undergoing segregation. Many of the accessions in the collection had at least one heterozygous site (Table 1, column 9).

\section{Factorial plot of the cowpea accessions}

General diversity of the germplasm is displayed in a factorial plot in Figure 3 and Additional file 2. Lines and a circle were drawn in Figure 3 to aid in explanation. Three major clusters were identified in the Figure demarcated by the "y" shaped two green lines. Members of each cluster were characterized mostly by similar seed coat colour.

\section{Dendrogram of the cowpea accessions}

Figure 4 is a dendrogram of the cowpea accessions drawn with the calculated values of dissimilarity using hierarchical clustering with WPGMA method. Accessions written in black represent genebank materials obtained from Bunso and WACCI01 while those in blue

Factorial analysis: haes $1 / 2$

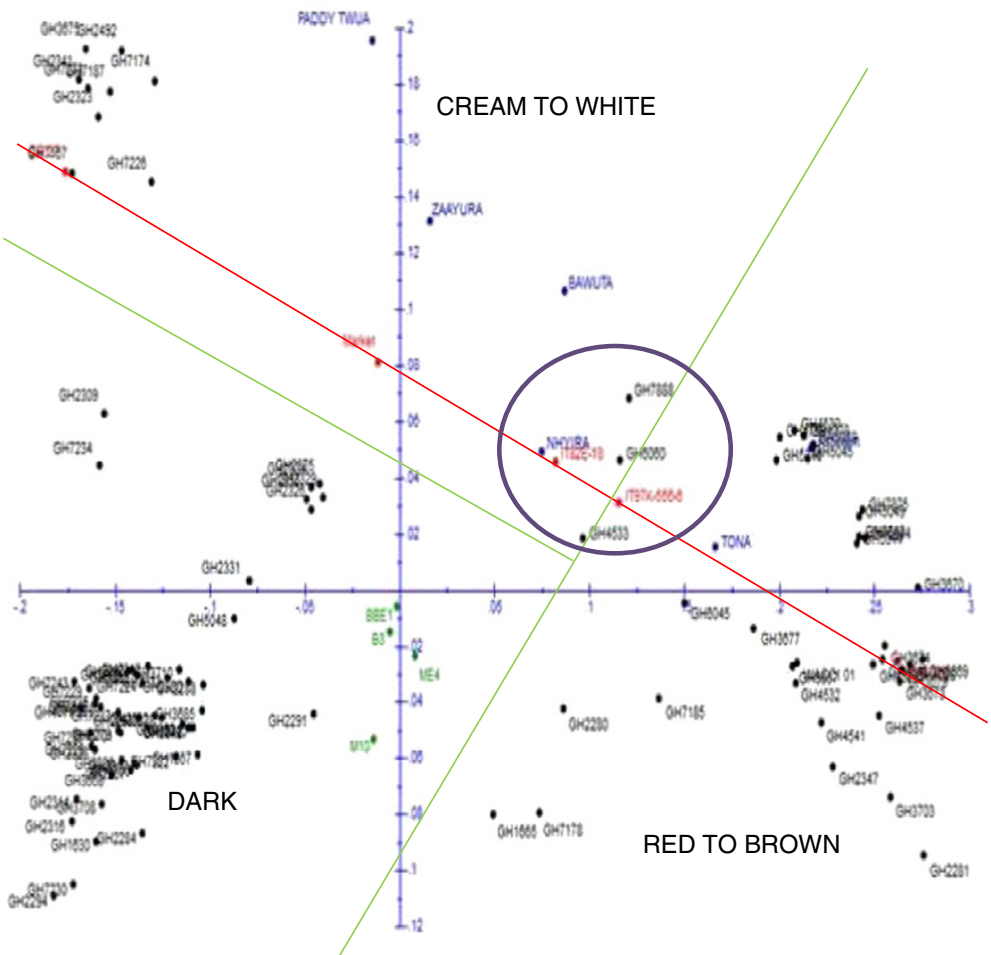

Figure 3 Factorial display of 113 cowpea accessions. 


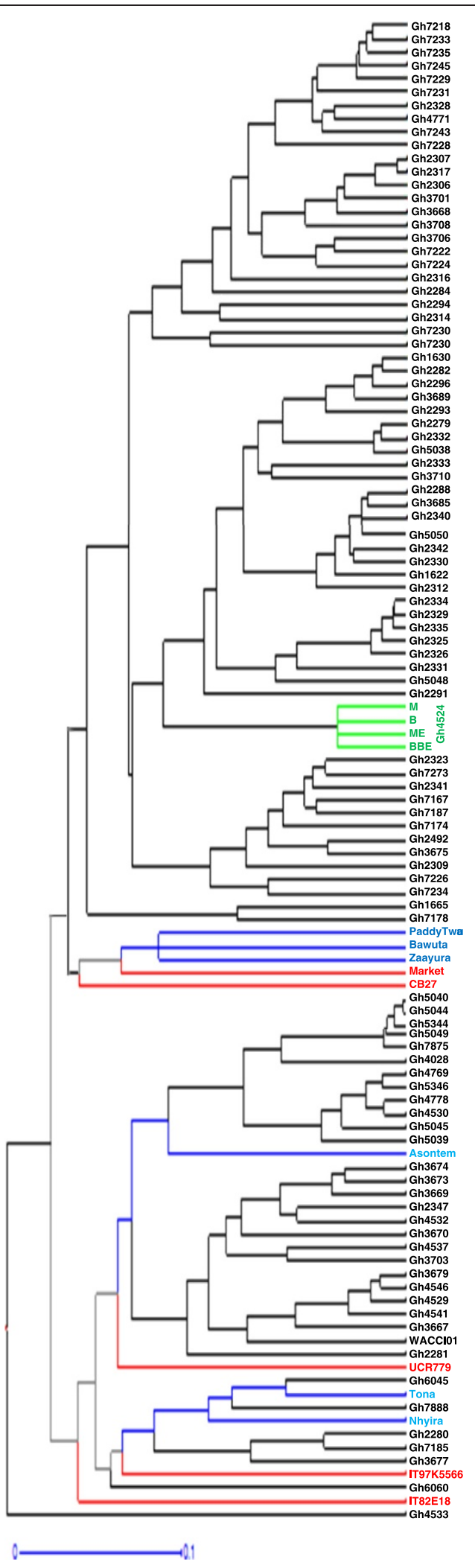

Figure 4 Dendrogram of 113 cowpea accessions constructed from dissimilarity using 458 polymorphic SNP markers. and green are improved varieties from Ghana and Gh4524 lines respectively. Accessions in red are from IITA, UCR and the one named "market". For legibility purposes, different portions of Figure 4 were shown in Figures 5, 6 and 7.

\section{Result of structure analysis}

The result of analysis made with Structure is presented in Figure 8. Each accession is represented by a vertical line, which is partitioned into coloured segments indicating the estimated membership fractions for it. Estimated Ln Prob. of data = -32014.2: Mean value of ln likelihood = 701.5: Mean value of alpha $=0.071$ : Mean value of Fst $1=$ 0.7: Mean value of Fst $2=0.56$ : Mean value of Fst $3=0.49$. Accessions in the same population in Figure 8 were collected from across the different agro-ecological zones of Ghana with no known history of genetic relationship between most of them.

\section{Core 48 accessions}

Maximum length sub tree method (Perrier et al. 2003) was used to identify forty-eight core accessions for breeding purposes (Figure 9). Accessions in red represent foreign materials; black for genebank materials, blue for improved varieties and green for Gh4524 line. These 48 accessions are very diverse morphologically. The core 48 accessions include UCR779, CB27, IT97K-556-6 and IT82E-18 which are internationally known cowpea lines. These materials have unique alleles that are not likely to be available in the genebank of PGRRI. Five of the improved varieties from Ghana such as 'Asontem' and 'Nhyira' are also in the core 48.

\section{Discussion}

For purposes of discussion, we denote those alleles present in not more than $10 \%$ of the studied collection as 'rare alleles'. The cowpea accessions, GH7888 (a genebank material), 'Zaayura' and IT97K-556-6 shared a rare allele. IT97K-556-6 is IITA line while 'Zaayura' is a commercial variety released by CSIR - Savanna Agricultural Research Institute. Another rare allele was shared by UCR779 and 'Zaayura'. UCR 779, a Botswana landrace, resistant to aphid (Muchero et al. 2009) was one of the most unique accessions in the collection. It was the only line with "A" against "T" for one marker. "Asontem" (IT82E-16) which is one of the improved varieties in Ghana developed by IITA in collaboration with CSIRCrops Research Institute, also had a rare allele at a locus. The last example of a rare allele observed in the collection was "T" for GH7167, GH2288 and CB 27 where all other accessions had " $\mathrm{C}$ ". The allelic diversity thus varied greatly for the studied cowpea accessions.

The 458 SNP markers were able to discriminate between all the cowpea accessions studied. Previous 


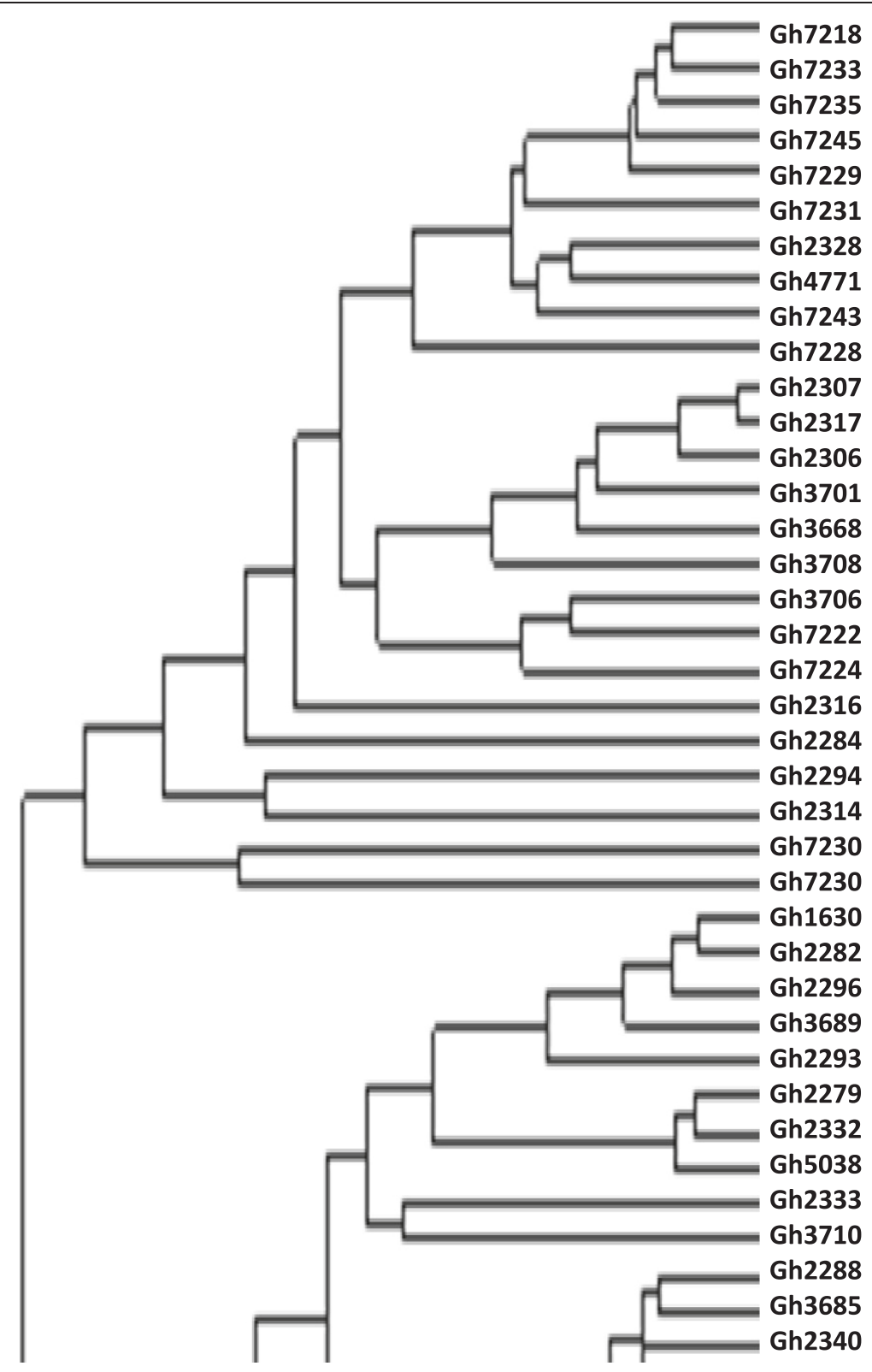

Figure 5 First 38 cowpea accessions in Figure 4.

studies (Bennett-Lartey 1992; Oppong-Konadu et al. 2005; Asare et al. 2010) could not discriminate all accessions, but the increase number of markers used here and their high levels of polymorphism allowed the discrimination of even closely related accessions such as BBE, M, B and ME (segregated lines of Gh4524). This confirms the robustness of SNP markers in diversity studies as reported by Varshney et al. (2007). The separation of the four Gh4524 lines on the other hand could most probably be due to segregation as Lucas et al. (2013a) were able to identify duplicates from the USDA' core cowpea collection with SNP markers.
Definite patterns were identified in the cowpea collection. Both Ghanaian and foreign elite accessions clustered together (Figures 3 and 4). Patterns could also be seen in Figure 4 based on the seed coat colour similarities of the cowpea accessions. However, accessions collected from different regions of Ghana did not cluster together in most cases. Asare et al. (2010) also did not observe strong geographic relationship in the PGRRI cowpea collection when they used SSR in diversity studies. Tanhuanpaa and Manninen (2012) in their studies on Phleum pretense with SSRs also did not observe significant correlation between the various accessions and their geographic 


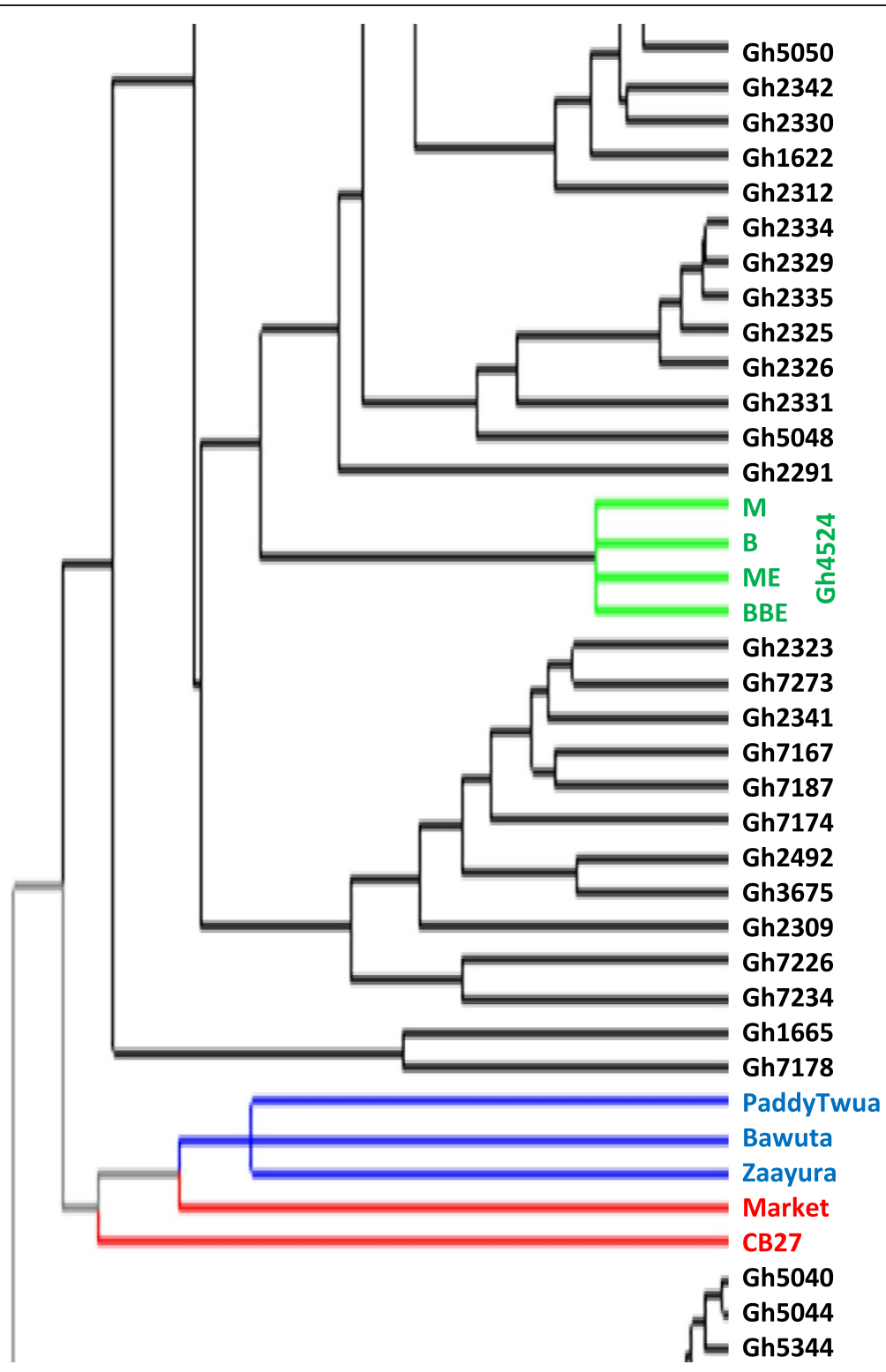

Figure 6 Middle 38 cowpea accessions in Figure 4.

origins. Geography does not always reflect underlying genetic structure (Rosenberg et al. 2002).

Only 150 markers which are about $30 \%$ did not have any cowpea showing heterozygosity. Some markers generally revealed higher levels of heterozygosity. There were 23 accessions heterozygous for a particular marker. Most of these accessions clustered together (Figures 3 and 4). Gh7234 for instance had as many as 90 heterozygous sites. This suggests that some of the genebank cowpea accessions are not pure. Phenotypic analysis strengthened the assertion that seeds of Gh7234 were different in terms of seed coat colours with the dominant as dark mottling. Similar observation was made for Gh7231 which had 13 heterozygous sites. However, some of the improved varieties including the foreign ones (IT97K-556 and CB27) also had one or more heterozygous sites. High heterozygosity known in such crops as plantains (Tenkouano et al. 1999), Scot pines (Gupta et al. 2001) and cassava (Dyer et al. 2011) was unanticipated in this study. The high heterozygosity observed in some of the cowpea accessions might be due to outcrossing (Lucas et al. 2011; Kouam et al. 2012) during regeneration at the genebank and to the fact that some of them have hybrid origin. There were only five accessions (Gh2282, Gh2340, Gh2347, Gh3706 and Gh7218) that were homozygote for all the loci.

Three major clusters are identified on the factorial display of the accessions indicated by two green lines which 


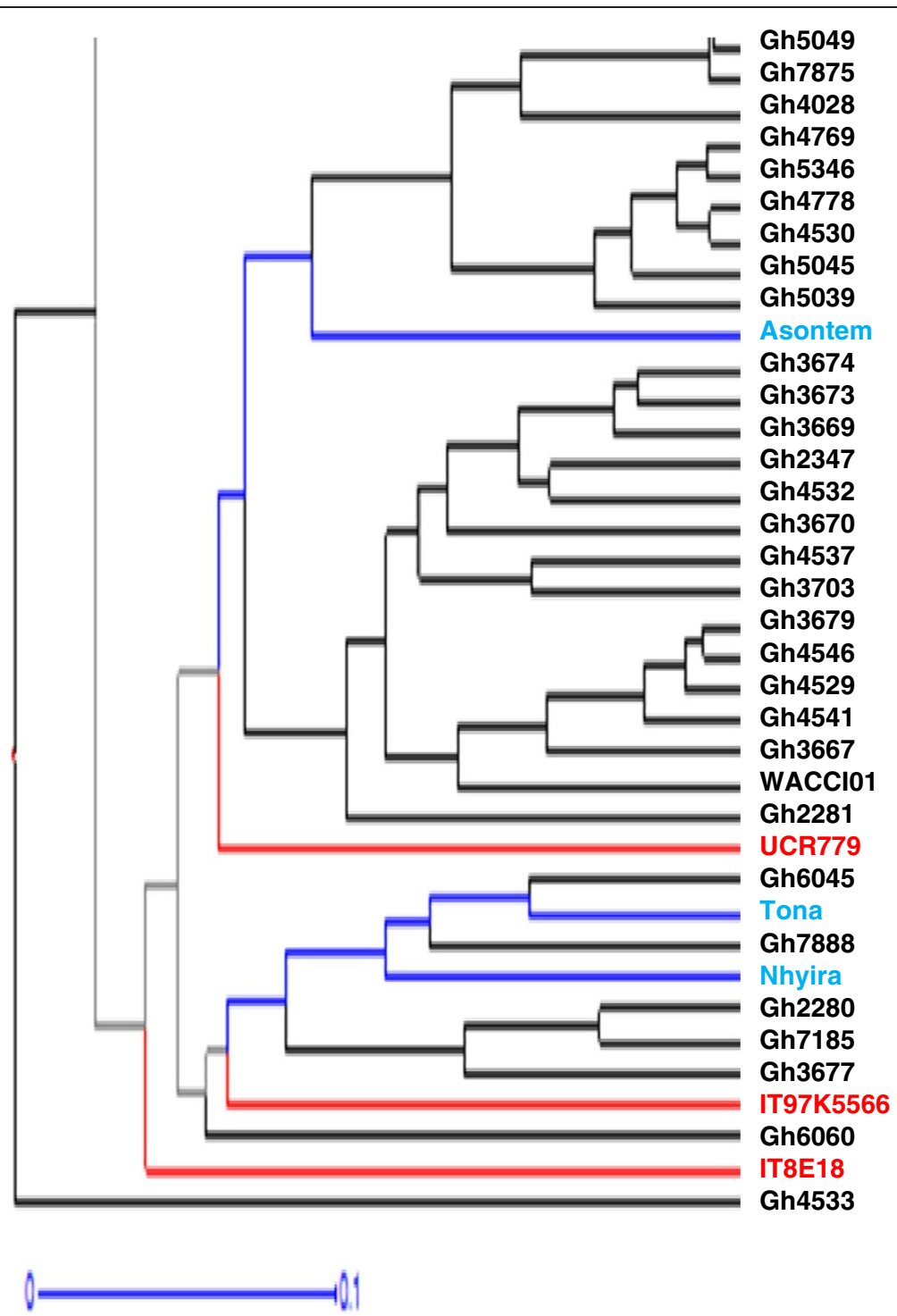

Figure 7 Final 37 accessions of Figure 4.

formed a "y" shape (Figure 3). Accessions of same cluster generally have similar seed coat colours with only few exceptions. Some of these exceptions are Gh2281 and Gh7185 with dark seed coat colours clustering in the red to brown seed coat colour group while Gh2284 and Gh5048 with red seeds clustered with dark colours. Seed coat colour is a frequently used as a morphological trait in classifying crop varieties (Adesoye and Ojobo 2012) and may also be linked with other important traits (Atis et al. 2011). The clusters according to the seed coat colours are; Dark, Cream to White and Brown to Red (Figure 3). The boundaries between the dark seed coat colour cluster and the other two were very conspicuous. However, the boundary between the white and red seed coat colour clusters was not very clear. Six accessions in the purple outlined circle formed a sub-cluster between the white and red seed coat colour clusters. Even though, the six accessions formed a sub-cluster, each individual was closely linked to its respective major cluster, with the exception of IT82E-18 (Figure 3). In contrast, Asare et al. (2010) did not observe clustering pattern based on seed coat colour when they characterized cowpea collection with SSRs. However, in this study clear pattern based on seed coat colour was observed. Similarly in maize, SNP markers were used to identify kernel colour gene (Sharma et al. 2011).

All the foreign accessions fell on a straight line (red). Meaningfully, they also fell in their appropriate colour seed coat clusters. These are elite germplasm (improved varieties) and have been selected for similar traits over a 


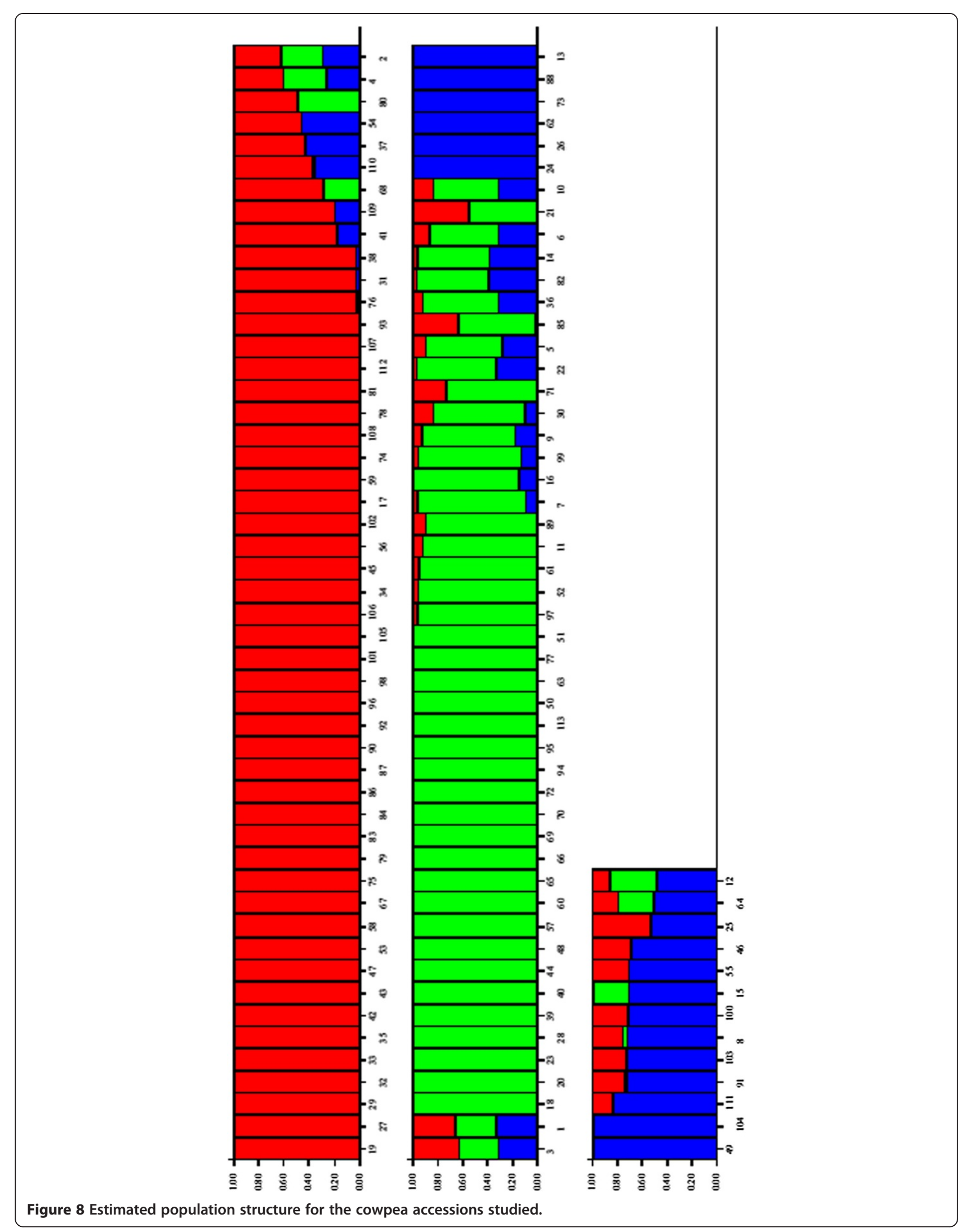




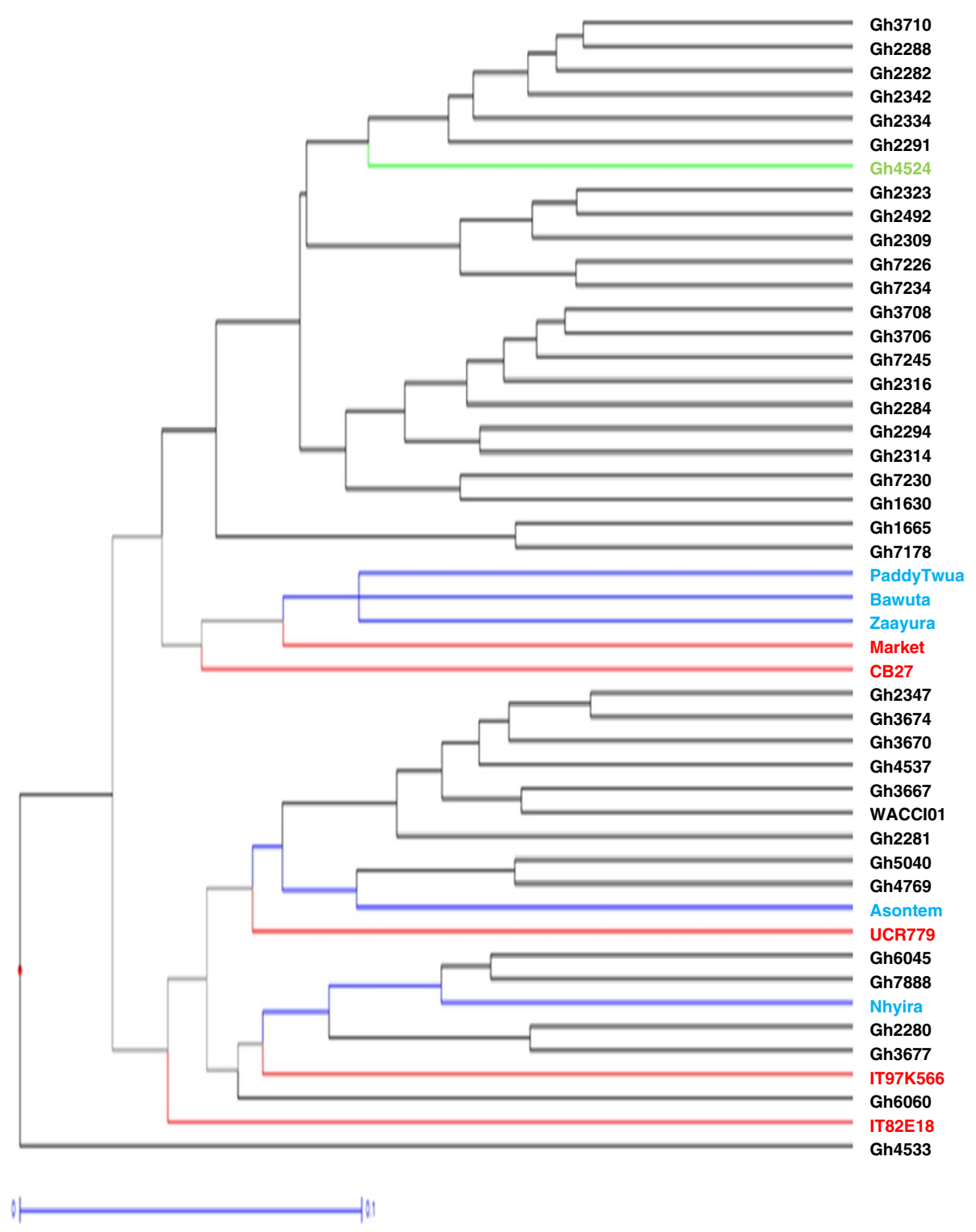

Figure 9 Dendrogram of 48 core cowpea accessions identified through Maximum Length Sub Tree method for conservation and breeding purposes.

long period of time. The improved varieties from both Ghana and abroad are found on or above the red line (Figure 3). Local accessions that clustered with these elite accessions could be very useful materials for cowpea breeding programmes, especially in Ghana, for being genetically close to the elite varieties and being adapted to the local climate. For instance, the dissimilarity between GH7888 (a genebank material), and 'Zaayura' was as small as 0.026. GH7167, GH2288 and CB 27 clustered together. CB27 was released in California in 1999 and is resistant to Fusarium wilt race 3 and moderately susceptible to aphid (Muchero et al. 2009). Phenotypically CB27 did not share much similarity with Gh2288. Seed mass of CB27 was twice that of Gh2288. The kidney shaped seed of CB27 had white seed coat with black eye. This type of cowpea has a high preference in Ghanaian markets (Langyintuo, 2003). Gh2288 on the other hand had dark mottling seed coat colour. Accession CB27 was erect while Gh2288 was prostrate. Few traits shared by CB27 and Gh2288 are, pigmented immature pod tip which dry up to straw, pendant pods and sub-hastate terminal leaflet that were slightly curved.

No elite genotype fell in the dark coat coloured cluster (Figure 3). Commercial varieties of cowpea are mainly white or brown to red coat coloured in Ghana as they are the types preferred by consumers (Quaye et al. 2011; Langyintuo et al. 2003). Separation of many Ghanaian accessions away from elite and commercial varieties may 
mean availability of diversity that could be exploited for cowpea improvement. Despite claims of limited genetic variation in cowpea (Asare et al. 2010; Kumar et al. 2011 Tan et al. 2012), there is substantial morphological and genetic evidence that cowpea is a very diverse taxon (Huynh et al. 2013). This experiment has shown that the studied germplasm has some amount of diversity that can be used for cowpea improvement. Furthermore the cowpea community should consider the many subspecies of cowpea and the tens of thousands of accessions collected from more than 50 countries that are available through different germplasm collections. Special interest would be to use the landraces in broadening the genetic base of the improved cowpea varieties similar to what was suggested for asparagus bean in China (Tan et al. 2012).

Clustering of materials such as CB27, Paddy Twua (Padi Tuya), 'Bawuta' and 'Zaayura' is very significant. This is because Padi 'Tuya' and a number of varieties released by CSIR - SARI are known to have parentage from California Black eye (Padi et al. 2004). Close relationship between "Market" and CB27 (Figures 3 and 4) was also not surprising. "Market" was an imported cowpea picked from a market and was suspected to originate from California Black-eye because of its seed features. Clustering of CB27 and Market had confirmed their relatedness. The dendrograms in Figures 6 and 7 support pedigree knowledge as seen in the clustering of Gh4524 lines and UCR779 with IT82E-18 which are both from South/East Africa, Botswana and Mozambique, respectively. The SNP markers were for that matter very reliable in this diversity study. An exception was that IT82E-18 did not cluster with Asontem (IT82E-18 in Ghana). It could probably be that the Asontem collected was not the IT82E-18 as it has been in the hands of farmers for a long time. Farmers might be calling a morphological similar variety Asontem. Another possibility resulting in the non-clustering of IT82E-18 and the supposed Asontem is that the plant genotyped as Asontem could be a rogue as described by Luca et al. (2013b).

Three populations were assumed and represented by different colours; blue, green and red with 8, 22 and 38 accessions discretely coming from them respectively (Figure 8). Thus the total number of accessions without admixed genome was 68 . Members in the blue population, some of which are Gh2323, Gh7167 and Gh7174 clustered at the top left corner in Figure 3. In the exception of Gh7178 (13 in Figure 5), all the accessions with entirely blue genome have white or cream seed coat colour. Gh2323 and Gh7273 which are both members of the blue population in Figure 8 were the closest relatives in Figure 4. The cowpeas in the green population in Figure 8 are mostly red seed coated and also showed close relationship in the dendrogram in Figure 4. Accessions such as Gh5039, Gh5040 and Gh5049 in the green population clustered together in Figure 3. Similar patterns were also observed for the red population in Figure 8. However, accessions in this group are more diverse in terms of seed coat colour. The clustering pattern in the dendrogram and factorial plot with "Darwin" thus had some similarities with that of "Structure". Some authors believe that the software Structure does not always create clusters that are consistent with evolutionary history of individuals in populations; however, it is one of the most frequently used software for cluster analysis (Kalinowski 2011). In this study the result of the structure analysis made biological sense especially when it is compared to the phenotype of the cowpea accessions and the analysis made with Darwin.

Different combinations of admixture genome for different cowpea accessions were observed. Some of the accessions had genome from two different populations while others were from all the three. All of the improved varieties had genome from different populations (Figure 5). "Zaayura", "CB27" and "Market" had similar patterns in the exception of having slightly different proportions for the various segments. These three varieties are believed to have been bred from materials with common parentage (Padi et al. 2004). The four accessions obtained from Gh4524 (numbers 1, 2, 3 and 4 in Figure 8) showed very similar patterns and had portions of their genome from different sources. Some other accessions from the genebank as well showed inheritance of genome from different populations. Cowpea is predominantly inbreeding and it is shown by the mean apha value of 0.07 indicating that most of the accessions are essentially from one population. However, mean value of $3.4 \%$ outcrossing has been reported (Kouam et al. 2012) which might be the reason for some of the genebank materials to be admixed. The observation in this study thus confirms this phenomenon.

The establishment of a core germplasm collection helps in easy management and identification of variations for breeding purposes (van Hintum et al. 2000). Where the germplasm collection is very large, management goes beyond core to mini core collection (Upadhyaya et al. 2010). Forty-eight core accessions were consequently, identified from the fingerprinting for conservation and crop improvement. The core 48 accessions include UCR779, CB27, IT97K-556-6 and IT82E-18 which are internationally known cowpea lines. These materials had unique alleles that are not likely to be available in the genebank in Ghana. Five of the improved varieties from Ghana were included in the 48 core accessions. These 48 accessions include all of the 11 improved varieties in the study. Bringing these improved accessions which were hitherto not in the collection into the activities of the genebank might mean expansion of the gene pool of the cowpea which is considered to be narrow (Tan et al. 2012). 
Expansion of gene pool is important for crop improvement (Varshney et al. 2007).

The sphericity index as explained by Perrier et al. (2003) was considered in choosing the 48 core cowpea accessions. The sphericity index for all the 113 accessions was 0.69 . This figure meant that there was much redundancy in the collection, compared to the final three accessions which had the highest sphericity index of 1 . The core 48 accessions selected had sphericity index of 0.79 which was quite low indicating much redundancy which could permit further reduction in the number of accessions included in the core. However, as much as 10 improved varieties were included in the core when the number of accessions was reduced to 20 with sphericity index of 0.88 . This meant that with 20 core accessions, only $50 \%$ would be from the genebank. To avoid further narrowing of the genetic base of the cowpea germplasm for breeding purposes (Sharawy and El-Fiky 2002; Fang et al. 2005; Asare et al. 2010; Tan et al. 2012), the 48 core accessions were, therefore, accepted to increase the genetic base of the core.

The core accessions varied in morphological traits such as growth habit where there were a wide range spanning from erect to spreading types. Plant pigmentation, leaf shape and flower colour also varied among the core accessions. Seeds with different coat colours, sizes and shapes were found within the core accessions. Some of the accessions in the core collection had been reported to have resistance to biotic stresses. Examples include CB27 and UCR779 which are resistant to Fusarium wilt and aphid respectively (Muchero et al. 2009). These accessions could be used as parents to develop varieties resistant to biotic stresses such as aphid borne mosaic virus which is a serious constraint to cowpea cultivation in many parts of Africa (Orawu et al. 2012). Further evaluation of the core 48 accessions may reveal other traits that might be of interest to cowpea breeders.

\section{Conclusion}

This study was one of the earliest diversity studies in cowpea using SNP markers. The markers were efficient in discriminating between all the accessions used in the study including closely related materials such as Gh4524 lines. Accessions known to be related by ancestry such as CB27 and Paddy Twua, clustered together, demonstrating the reliability of the markers. The information provided in this diversity study could be useful in cowpea improvement in Ghana and elsewhere. A total of 48 accessions were identified as a core collection for breeding purposes. These core accessions were morphologically very diverse and included UCR779, CB27, IT97K-556-6 and IT82E-18. These are elite materials obtained from different countries. Improved varieties from Ghana such as 'Asontem' and 'Nhyira' are also in the 48 core accessions.
The genetic diversity of the selected core could be of importance for future plant breeding for the development of superior varieties of cowpea.

\section{Additional files}

Additional file 1: Raw SNP Genotype Data used for Analyses.

Additional file 2: Factorial plot of the cowpea accessions.

\section{Competing interests}

The authors declare that they have no competing interests.

\section{Authors' contributions}

KF Egbadzor is the Principal Investigator; K Ofori, EY Danquah, SK Offei and M Yeboah were the principal investigator's PhD. Supervisors. They, therefore, gave guidance at each stage of the experimentation and writing of the manuscript. MO Opoku-Agyeman assisted in the data analyses. LM Aboagye corrected the first draft of the manuscript. All authors read and approved the final manuscript.

\section{Acknowledgement}

We are indebted to the Generation Challenge Programme and the Alliance for a Green Revolution in Africa for financing the research. We thank management and staff of CSIR - PGRRI, Bunso, Ghana and Prof. J. Ehlers of California Riverside University for providing the cowpea samples for the experiment. We also thank Mr. Edward Addo for assisting in sampling and packaging of the experimental materials for genotyping.

\section{Author details}

${ }^{1}$ West Africa Centre for Crop Improvement, University of Ghana, Legon, Accra, Ghana. ${ }^{2}$ CSIR - Plant Genetic Resources Research Institute, Bunso, Ghana. ${ }^{3}$ Cocoa Research Institute of Ghana, Tafo, Ghana. ${ }^{4}$ The Biotech Centre - University of Ghana, Legon, Accra, Ghana. ${ }^{5}$ Department of Crop Science, University of Ghana, Legon, Accra, Ghana.

Received: 24 July 2014 Accepted: 9 September 2014

Published: 20 September 2014

\section{References}

Acquaah G (2007) Principles of Plant Genetics and Breeding. Blackwell Publishing, 350 Main street, Malden, MA 02148-5020, USA, p P249

Adesoye Al, Ojobo OA (2012) Genetic diversity assessment of Phaseolus vulgaris L. landraces in Nigeria's mid-altitude agroecological zone. Int J Biodivers Conserv 4(13):453-460

Asare AT, Gowda BS, Galyuon IKA, Aboagye LM, Takrama JF, Timko MP (2010) Assessment of the genetic diversity in cowpea (Vignaunguiculata (L.) Walp) germplasm from Ghana using simple sequence repeat markers. Plant Genet Resour - C 8(2):142-150

Atis I, Atak M, Can E, Mavi K (2011) Seed coat color effects on seed quality and salt tolerance of red clover (Trifolium pratense). Int J Agric Biol 13:363-368

Bennett-Lartey SO (1992) Plant genetic resources activities in Ghana. A status report. In: Liang E, Ameyaa-Akumfi C, Enu-Kwesi L, Oteng-Yeboah AA, Gyasi EA, Rudat H, Acheampong E, Bennett-Lartey SO (eds) Proceedings of the workshop on Bioversity. University of Ghana, Legon, Accra, 8th January 1992

Boukar O, Massawe F, Muranaka S, Franco J, Maziya-Dixon B, Singh B, Fatokun C (2011) Evaluation of cowpea germplasm lines for protein and mineral concentrations in grains. Plant Genet Resour - C 9(4):515-522

Cobbinah FA, Addo-Quaye AA, Asante IK (2011) Characterization, evaluation and selection of Cowpea (Vigna unguiculata (L.) Walp) Accessions with desirable traits from eight Regions of Ghana. ARPN J Agric Biol Sci 6(7):21-32

Deulvot C, Charrel H, Marty A, Jacquin F, Donnadieu C, Lejeune-Hénaut I, Burstin J, Aubert G (2010) Highly-multiplexed SNP genotyping for genetic mapping and germplasm diversity studies in pea. BMC Genomics 11:468, http://www.biomedcentral.com/1471-2164/11/468

Dyer GA, Gonzalez C, Lopera DC (2011) Informal "Seed" Systems and the Management of Gene Flow in Traditional Agroecosystems: The Case of Cassava in Cauca, Colombia. PLoS One 6(12):e29067, doi:10.1371/journal. pone.0029067 
Fang J, Devanand PS, Chao CCT (2005) Genetic diversity of cowpea [Vigna unguiculata (L.) Walp] breeding lines from different countries determined by AFLP markers, Poster section 4 - Genetics and germplasm, 102nd annual conference on international conference of the America Society of Horticultural Science. Las Vegas, Nevada, USA

Galeano CH, Gomez M, Rodriguez LM, Blair MW (2009) CEL I nuclease digestion for SNP discovery and marker development in common bean (Phaseolus vulgaris L.). Crop Sci 49(2):381-394

Gupta PK, Roy JK, Prasad M (2001) Single nucleotide polymorphisms: a new Paradigm for molecular marker technology and DNA polymorphism detection with emphasis on their use in plants. Curr Sci 80(4):524-535

Huynh B, Close TJ, Roberts PA, Hu Z, Wanamaker S, Lucas MR, Chiulele R, Cissé N, David A, Hearne S, Fatokun C, Diop NN, Ehlers JD (2013) Gene Pools and the Genetic Architecture of Domesticated Cowpea. Plant Genome 6:3

Kalinowski ST (2011) The computer programme STRUCTURE does not reliably identify the main clusters within species: simulations and implications for human population structure. Heredity 106:625-632

Kouam EB, Pasquet RS, Campagne P, Tignegre J, Thoen K, Gaudin R, Ouedraogo JT, Salifu AB, Muluvi GM, Gepts P (2012) Genetic structure and mating system of wild cowpea populations in West Africa. BMC Plant Biol 12:113, doi:10.1186/1471-2229-12-113

Kumar J, Choudhary AK, Solanki RK, Pratap A (2011) Towards marker-assisted selection in pulses: a review. Plant Breeding 130:297-313

Langyintuo AS, Lowenberg-DeBoer J, Faye M, Lambert D, Ibrod G, Moussa B, Kergna A, Kushwaha S, Musa S, Ntoukam G (2003) Cowpea supply and demand in West and Central Africa. Field Crop Res 82:215-231

Lucas MR, Diop NN, Wanamaker S, Ehlers JD, Roberts PA, Close TJ (2011) Cowpea-Soybean Synteny Clarified through an Improved Genetic Map. Plant Genome 4(3):218-225

Lucas MR, Huynh B, Cisse N, Drabo I, Ehlers JD, Roberts PA, Close TJ (2013a) Association studies and legume synteny reveal haplotypes determining seed size in Vigna unguiculata. Front Plant Sci 4(95). doi:10.3389/fpls.2013.00095

Lucas MR, Huynh B, Ehlers JD, Roberts PA, Close TJ (2013b) High-resolution single nucleotide polymorphism genotyping reveals a significant problem among breeder resources. Plant Genome 6(1):1-5

Manifesto MM, Schlatter AR, Hopp HE (2001) Quantitative evaluation of genetic diversity in wheat germplasm using molecular markers. Crop Sci 41(3):682-690

Muchero W, Diop NN, Bhat PR (2009) A consensus genetic map of cowpea [Vigna unguiculata $(\mathrm{L})$ Walp.] and synteny based on EST-derived SNPS. Proc Natl Acad Sci U S A 106(43):18159-18164

Obembe $O O$ (2008) Exciting times for cowpea genetic transformation research. J Life Sci 5(2):50-52

Oppong-Konadu EYR, Akromah HK, Adu-Dapaah OE (2005) Genetic diversity within Ghanaian cowpea germplasm based on SDS - PAGE. Afr Crop Sci J 13(2):117-123

Orawu M, Melis R, Mark Laing M, Derera J (2012) Genetic inheritance of resistance to cowpea Aphid-borne mosaic virus in cowpea. Euphytica. Int J Plant Breed 74(1). doi:10.1007/s10681-012-0756-3

Padi FK, Denwar NN, Kaleem FZ, Salifu AB, Clottey VA, Kombiok J, Haruna M, Hall AE, Marfo KO (2004) Registration of 'Marfo-Tuya' cowpea. Crop Sci 44:1486-1487

Perrier $X$, Jacquemoud-Collet JP (2006) DARwinsoftware., http://darwin.cirad.fr/darwin

Perrier X, Flori A, Bonnot F (2003) Data analysis methods. In: Hamon P, Seguin M, Perrier X, Glaszmann JC (eds) Genetic Diversity of Cultivated Tropical Plants. Enfield, Science Publishers, Montpellier, pp 43-76

Pritchard JK, Stephens M, Donnelly P (2000) Inference of population structure using multilocus genotype data. Genetics 155:945-959

Quaye W, Adofo K, Buckman SE, Frempong G, Jongerden J, Ruivenkamp G (2011) A socio-economic assessment of cowpea diversity on the Ghanaian market: implications for breeding. Int J Consum Stud 35:679-687

Rosenberg NA, Pritchard JK, Weber JL, Cann HM, Kidd KK, Zhivotovsky LA, Feldman MW (2002) Genetic structure of human populations. Science 298:2381-2385

Sharawy WM, El-Fiky ZA (2002) Characterization of cowpea (Vigna unguiculata L.) accessions based on yield traits and RAPD-PCR analyses. Arab J Biotech 6(1):67-78

Sharma M, Cortes-Cruz R, Ahern MK, McMullen M, Thomas P, Brutnell TP, Chopra S (2011) Identification of the Pr1 Gene Product Completes the Anthocyanin Biosynthesis Pathway of Maize. Genetics 188:69-79
Tan H, Tie M, Luo Q, Zhu Y, Lai J, Li H (2012) A review of molecular makers applied in Cowpea (Vigna unguiculata L.Walp.) Breeding. J Life Sci 6(2012):1190-1199

Tanhuanpaa P, Manninen O (2012) High SSR diversity but little differentiation between accessions of Nordic timothy (Phleum pratense L.). Hereditas 149:114-127

Tenkouano A, Crouch JH, Crouch HK, Vuylsteke D, Ortiz R (1999) Comparison of DNA marker and pedigree-based methods of genetic analysis in plantain and banana (Musa spp.) clones. II. Predicting hybrid performance. Theor Appl Genet 98:69-75

Timko MP, Singh BB (2008) Cowpea a multifunctional legume. In: More PH, Ming R (eds) Genomics of Tropical Crops Plants., pp 237-238

Upadhyaya HD, Yadav D, Dronavalli N, Gowda CLL, Singh S (2010) Mini core germplasm collections for infusing genetic diversity in plant breeding programs. Electron J Plant Breed 1(4):1294-1309

van Hintum TJL, Brown AHD, Spillane C, Hodgkin T (2000) Core Collections of Plant Genetic Resources. IPGRI Technical Bulletin No. 3. International Plant Genetic Resources Institute, Rome, Italy

Varshney RK, Chabane K, Hendre PS, Aggarwal RK, Graner A (2007) Comparative assessment of EST-SSR, EST-SNP and AFLP markers for evaluation of genetic diversity and conservation of genetic resources using wild, cultivated and elite barleys. Plant Sci 173:638-649

doi:10.1186/2193-1801-3-541

Cite this article as: Egbadzor et al.: Diversity in 113 cowpea [Vigna unguiculata (L) Walp] accessions assessed with 458 SNP markers. SpringerPlus 2014 3:541.

\section{Submit your manuscript to a SpringerOpen ${ }^{\odot}$ journal and benefit from:}

- Convenient online submission

Rigorous peer review

- Immediate publication on acceptance

- Open access: articles freely available online

- High visibility within the field

- Retaining the copyright to your article

Submit your next manuscript at $>$ springeropen.com 